www.jmscr.igmpublication.org

Impact Factor 5.244

Index Copernicus Value: 83.27

ISSN (e)-2347-176x ISSN (p) 2455-0450

crossref DOI: _https://dx.doi.org/10.18535/jmscr/v4i12.62

\title{
Multicentric Reticulohistiocytosis, A Rare Cause of Polyarthritis with Skin Manifestations in Paediatric Age Group: A Case Report
}

\author{
Authors \\ Dr Hriday De ${ }^{1}$, Dr Mandira Roy ${ }^{2}$, Dr Priyankar Pal ${ }^{3}$, Dr Prabhas Prasun Giri ${ }^{4}$, \\ Dr Deepshikha Mishra ${ }^{5}$ \\ 1,2,3,4,5 Institute of Child Health, Kolkata, India \\ Email: ${ }^{2}$ drmandiraroy@gmail.com, ${ }^{3}$ drdeepshikhamishra@gmail.com, ${ }^{4}$ drprabhasgiri@gmail.com, \\ ${ }^{5}$ mailme.priyankar@gmail.com \\ Corresponding Author \\ Dr Hriday De \\ Institute of Child Health, Kolkata \\ Postal address: Institute of Child Health, 11 Dr. Biresh Guha Street, Kolkata -700017, Country- India \\ Email : hridayde2010@gmail.com
}

\begin{abstract}
:
Backgound: Multicentric reticulohistiocytosis is a rare proliferative histiocytic disease of unknown etiology with potentially disabling nature. Primary manifestations are involvement of skin as paulonodular leisons and arthritis. The articular destruction can lead to permanent joint deformities.

Case Presentation: Our patient is a 11 year old boy presented with polyarthritis and reddish-brown papulonodular cutaneous lesions. The diagnosis of multicentric reticulohistiocytosis was confirmed by histopathological examination of skin nodules that was further substantiated by immunohistochemistry. The boy responded with oral corticosteroids and subcutaneous methotrexate injection.

Conclusion: Though Multicentric reticulohistiocytosis (MRH) is a rare condition in pediatric patients, but it is with potentially disabling nature, timely diagnosis and treatment with immunosuppressant can controll this disease process.
\end{abstract}

\section{Background}

Multicentric reticulohistiocytosis (MRH), also known as lipoid dermoarthritis, is a rare systemic disease of unknown etiology. It is characterized by the infiltration of histiocytes and multinucleated giant cells in synovial lining of joints and skin leading to massive symmetric osteoarticular destruction followed by nodular cutaneous eruptions. Systemic complications and malignancy may also be associated with MRH. Most patients present with aggressive symmetric polyarthritis affecting peripheral joints, most commonly involving interphalangeal joints of the fingers. Eventually, if not treated properly,all synovial lined joints become affected, with mutilant arthritis as an end result in nearly half of the cases. ${ }^{[1,2]}$ Histiocytic cells of MRH are best characterized using immunohistochemistry by their immunoreactivity to CD68 and CD45 and non-reactivity for S-100 protein, CDIa, CD34 and 


\section{JMSCR Vol||04||Issue||12||Page 14685-14688||December}

factor XIIIa. ${ }^{[3]} \mathrm{A}$ variety of drugs have been used for the treatment of MRH, with immunosuppressive drugs like methotrexate and cyclophosphamide being the most useful.[9]Our proband, a classical case of MRH with systemic symptoms responded very well to Steroids and methotrexate.

\section{Case Presentation}

$11 \mathrm{yr}$ old male child presented with cervical lymphadenopathy, fever, generalised papulonodular skin lesions with arthritis affecting multiple large and small joints for 1 month.

Physical examination revealed discrete, firm, reddish-brown, nontender papules and nodules ranging from $2 \mathrm{~mm}$ to $2 \mathrm{~cm}$ over the elbows, trunk, thigh, ears, both upper limbs (Fig.1) ; and arthritis of wrists, metacarpophalangeal, proximal and distal interphalangeal joints, knees, ankles and elbows,. The child was febrile with bilateral cervical lymphadenopathy and enlarged liver. Vitals and other systemic examination were within normal limit. Initial investigation showed high total count (33600), with neutrophilic preponderance, hemoglobin 11.1, peripheral blood smear showed no abnormal cell, CRP was $136 \mathrm{mg} / \mathrm{dl}$, ESR 112. CXR, LFT, RFT, viral serology, Mantoux, Blood C/S all were normal. USG abdomen showed hepatomegaly. Xray wrist and ankle joint showed periosteal reaction( figure 2). Bone marrow study was normal, lymphnode biopsy showed reactive hyperplasia. On skin biopsy dermis showed patchy interstitial and perivascular polymorphic cell infiltrate with abundance of histiocytic cells and macrophages compatible with a histiocytic disorder(figure 3). The skin tissue screened for CD 1a, S-100 proteins and CD20, CD3 were negative. So our patient had histiocytosis which by immunohistochemistry was negative for Langerhans cell histiocytosis and lymphoma. On the basis of clinical presentation, radiology and histology the child was diagnosed to be suffering from multicentric reticulohistiocytosis (MRH).

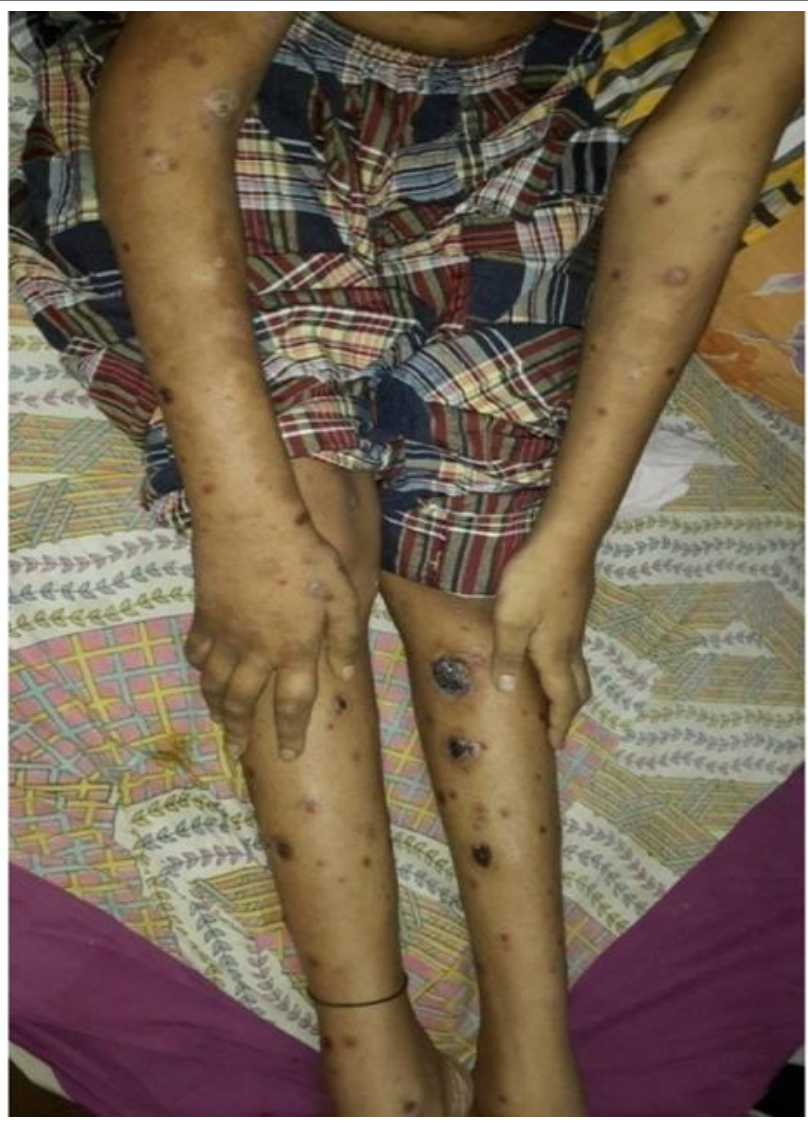

Figure 1: Papulonodular Skin Leisons

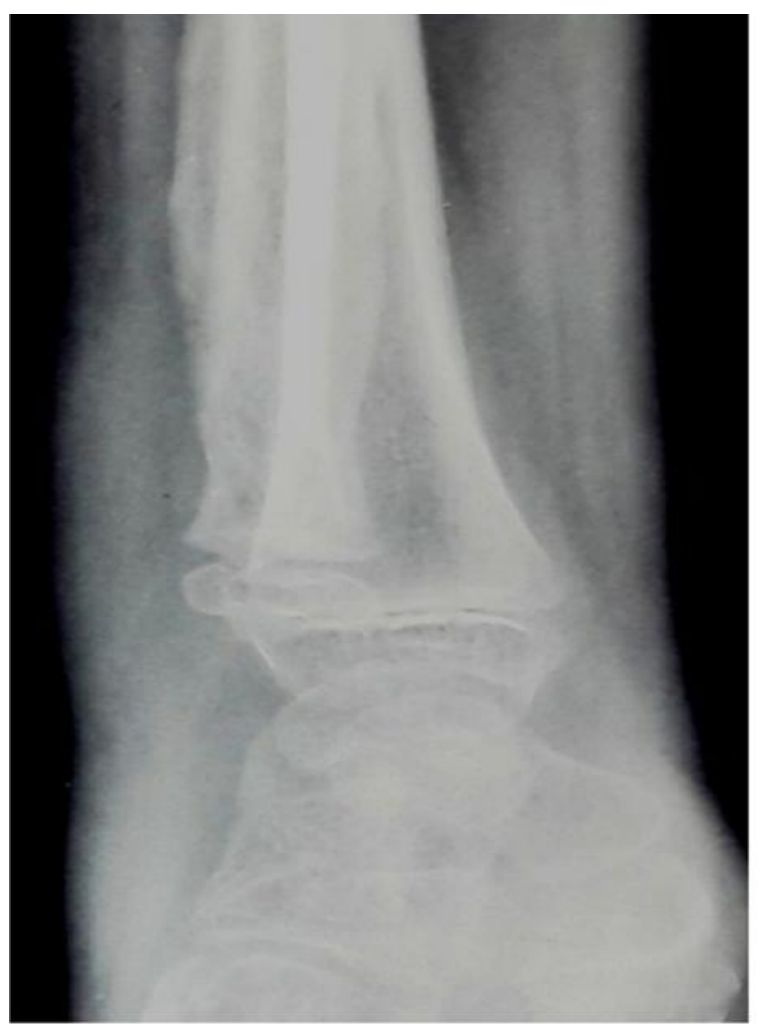

Figure 2: Xray Ankle Joint Showing Periosteal Reactions 


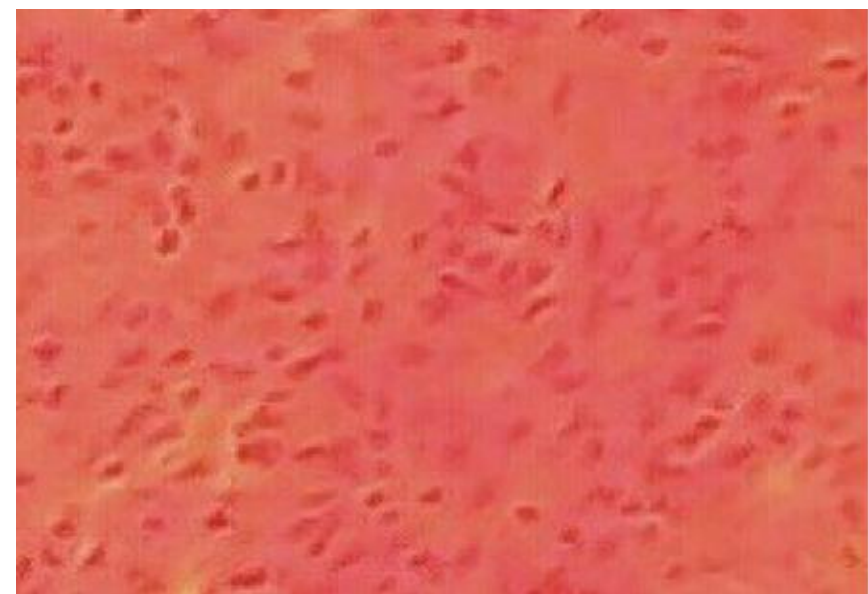

Figure 3: Skin Biopsy Microscopy Showing Abundance of Histiocytes.

\section{Discussion}

MRH is a rare condition of unknown etiology characterized by the infiltration of histiocytes and multinucleated giant cells in synovial lining of joints and skin leading to massive symmetric osteoarticular destruction followed by nodular cutaneous eruptions ${ }^{[1,2]}$; with usual onset in the 5 th decade of life, females predominate (60-75\%), and present with isolated polyarthritis (50\%), cutaneous lesions $(25 \%)$ or both concurrently $(25 \%)^{(3)}$. The polyarthritis is usually diffuse, symmetric, progressive, and destructive, with a predilection for the distal interphalangeal joint ${ }^{(4)}$. Skin lesions are usually asymptomatic, discrete, firm, skin-colored to reddish-brown nontender nodules, varying in size from several millimeters to several centimeters, occurring most frequently over the face, scalp, dorsum of the hands, ears, neck, forearms and elbow. Small tumefactions around the nail folds, termed coral beads, are characteristic. MRH has also been reported in association with lymphadenopathy, autoimmune diseases and malignancy ${ }^{(2)}$.

Immunohistochemical studies have shown that cytokines may contribute to synovial cell proliferation and bony erosions. Nakajima et al. demonstrated that histiocytes in MRH were positive for IL-1 $b$, and PDGF-B. The presence of TNF-a, a proinflammatory cytokine described in MRH is also known to be increased in other histiocytoses and erosive arthrides. Immunohistochemistry for histiocytic cells of MRH shows reactivity to $\mathrm{CD} 68$ and $\mathrm{CD} 45$ and non-reactivity for S-100 protein, CDIa, CD34 and factor XIIIa ${ }^{[2]}$ which is consistent with a monocyte-macrophage origin that is non-Langerhanic and non-dermal dendritic in nature. ${ }^{(5,6)}$

Because of the rare incidence and its unclear etiopathogenesis, there are no specific therapeutic guidelines. The use of prednisone, hydroxychloroquine, cyclophosphamide, chloram-bucil, methotrexate and azathioprine has been mentioned in the literature ${ }^{(7,9)}$. Recent reports on treatment using anti-TNF agents like etanercept and infliximab in combination with traditional immunosuppressants seem to be promising ${ }^{(8)}$. In our patient, we used oral prednisolone and indomethacin with weekly inj. methotrexate and guided by the improvement steroid was gradually tapered off and stopped over six months. Presently he is asymptomatic on weekly methotrexate, the skin lesions have disappeared and there has been radiological healing of the bony lesions.

\section{Declarations}

Ethics approval and consent to participate: Ethics committee of Institute of child health, Kolkata (IEC REGN NO: ECR/359/Inst/WB/2013 had approved my work and had given permission for publishing it.

Consent for publication: we had taken consent from both the patient and his father before publishing it

Competing Interest: The authors declare that they have no competing interests

Funding: No funding was required for this case report

Acknowledgement: Not applicable

Availability of data and material: Data sharing not applicable to this article as no datasets were generated or analysed during the current study

\section{REFERENCES}

1. Yamada T, Kurohori YN, Kashiwazaki S, Fujibayashi M, Ohkawa T. MRI of multicentric reticulohistiocytosis. J Comput Assist Tomogr 1996 Sep-Oct; 20(5):838 40. 
2. Barrow MV, Holubar K. Multicentric reticulohistiocytosis - a review of 33 patients. Medicine 1969; 48: 287-305.

3. Luz FB, Gaspar TAP, Kalil-Gaspar N, Ramos-e-Silva M. Multicentric reticulohistiocytosis. J Eur Acad Dermatol Venereol 2001 Nov; 15(6):5 24-31

4. Kaul A, Tolat SN, Belgaumkar V, Mhaske CB. Multicentric reticulohistiocytosis. Indian J Dermatol Venereol Leprol 2010;76:404-7.

5. Salisbury JR, Hall PA, Williams HC, Mangi MH, Mufti GJ. Multicentric reticulohistiocytosis detailed immunophenotyping confirms macrophage origin. Am J of Surg Path 1990; 14(7): 687-693.

6. Nakajima Y, Sato K, Morita H Torikai S Hidano A, Nishioka K, Kashiwazaki S. Severe progressive erosive arthritis in multicentric reticulohistiocytosis: possible involvement of cytokines in synovial proliferation. J of Rheumatol 1992; 19(10): 1643-1646.

7. Sellam J, Deslandre CJ, Dubreuil F, Arfi S, Kahan A. Refractory multicentric reticulohistiocytosis treated by infliximab: two cases. Clin Exp Rheumatol 2005;23:97-9.

8. Kovach BT, Calamia KT, Walsh JS, Ginsburg WW. Treatment of multicentric reticulohistiocytosis with etanercept. Arch Dermatol 2004;140:919-21

9. Blanco JJ, Hernandez FJ, Cerezo JG, Garcia IS, Rubio FC, Rodriguez JJ. Multicentric reticulohistiocytosis. The long course of a rare disease. Scand J Rheumatol 2002; 31(2): 107. 